
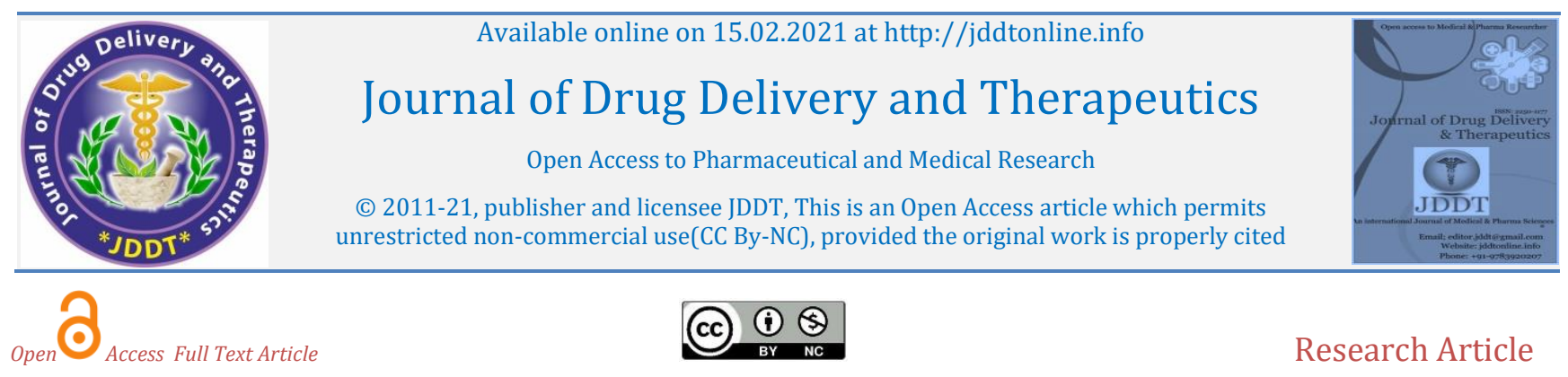

Research Article

\title{
Identification of potential inhibitors of SARS-CoV-2 from Artemisia annua compounds by In silico evaluation and their density functional theory (DFT)
}

\author{
Abdirahman ELMI ${ }^{*}$, Ahmed Said MOHAMED ${ }^{1}$, Nazia SIDDIQUI ${ }^{2}$, Syad AL JAWAD ${ }^{3}$, Moustapha NOUR ${ }^{4}$, \\ Idriss MIGANEH ${ }^{1}$ and Saleem JAVED ${ }^{5 *}$ \\ ${ }^{1}$ Medicinal Research Institute, Centre d'Etudes et de Recherche de Djibouti, IRM-CERD, Route de l'Aéroport, Djibouti \\ ${ }^{2}$ USIC, Dayalbagh Educational Institute, Agra, India 282005
}

${ }^{3}$ International Islamic University Chittagong, Department of pharmacy, Bangladesh

${ }^{4}$ Centre d'Etudes et de Recherche de Djibouti, ISV-CERD, Route de l'Aéroport, Djibouti

${ }^{5}$ Department of Chemistry, Institute of H. Science, Dr. B. R. Ambedkar University, Agra, India 282002

\begin{tabular}{ll}
\hline Article Info: & \\
\hline Article History: & \\
Received 13 Dec 2020; & \\
Review Completed 27 Jan 2021 & Accepted 02 Feb 2021; \\
Available online 15 Feb 2021 & \\
\hline
\end{tabular}

*Address for Correspondence:

Abstract

Abdirahman ELMI, Medicinal Research Institute, Centre d'Etudes et de Recherche de Djibouti, IRM-CERD, Route de l'Aéroport, Djibouti. Email : abelfourreh@hotmail.com

Saleem JAVED, Department of Chemistry, Institute of $H$.

Science, Dr. B. R. Ambedkar University, Agra, India 282002

Email : saleem.7javed@gmail.com

\section{Cite this article as:}

Elmi A, Mohamed AS, Siddiqui N, Al Jawad S, Nour M, Miganeh I, Javed S, Identification of potential inhibitors of SARS-CoV-2 from Artemisia annua compounds by In silico evaluation and their density functional theory (DFT), Journal of Drug Delivery and Therapeutics. 2021; 11(1-s):71-82 DOI: http://dx.doi.org/10.22270/jddt.v11i1-s.4702

\begin{abstract}
The genus Artemisia has recognized medicinal value and its use by humans Dates back to centuries ago. With the appearance of the new coronavirus, end of 2019 , several countries have recommended the use of herbal teas consisting mainly of Artemisia. The individual analysis of the constituents of this species is crucial to characterize and optimize its antiSARS-Cov- 2 action. We evaluated by molecular docking the inhibitory action of major compounds of the Artemisia genus (Artemisinin, Arteannuin B, Alpha Thujone, P-Hydroxyacetophenone, Fisetin, Cirsimaritin, Capillin, $\beta$-Sitosterol, and Quercetin) against three targets namely SARS-CoV-2 main protease (Mp), SARS-CoV-2 receptor binding domain (RBD) and human furin protease (HF protease). The two flavonols, quercetin and fisetin, have the best binding energies with the three targets. Quercetin/Fisetin possesses binding energy of $-7.17 /-6.9,-6.3 /-6.15$ and $-5.98 /-5.49 \mathrm{kcal} / \mathrm{mol}$ with MP, RBD and $\mathrm{HF}$ protease respectively. Their physicochemical properties meet the requirements of an oral active principle and are not toxic according to predictive simulations. Thereby DFT calculation has been used to analyze the electronic and geometric characteristics of these two compounds. The gap energies were also deduced for the stable structure and their reactivity. The abundance of Quercetin in different plants may be another advantage in the use of this bio-compound in the treatment of coronavirus.
\end{abstract}

Keywords: Artemisia annua, DFT, Docking Molecular, SARS-Cov-2, Quercetin and Fisetin

\section{INTRODUCTION}

Artemisia is one of the most widespread genera in the Asteraceae family. It is a heterogeneous genus, composed of more than 500 different species distributed mainly in the temperate zones ${ }^{1}$.

A large number of studies have been carried out to determine precisely the chemical compositions of the Artemisia species, especially for the two species A. annua and A. afra which have high medicinal value. Sesquiterpene lactones, phenolic compounds and flavones have been identified in $A$. annua 2-7 and $A$. afra contains monoterpenoids, sesquiterpenes, glaucolides, guaianolides, flavonoids ${ }^{8}$.
Many Artemisia-like plants exhibit strong antiviral properties. One of the first studies was carried out by M. M. Abid Ali Khan and al., in 1991 regarding the evaluation of inhibitory activity against tobamovirus. This work has shown promising results for some of the tested plant extracts such as $A$. annua. The active virus inhibitor effect has been shown to be the result of the presence of a mixture of lowmolecular-weight sterols ${ }^{9}$.

Also another study showed that $A$. annua has an antiviral potential greater than that of 20 other medicinal plants tested. The good antiviral activity of $A$. annua can be explained by the presence of sterols having better antiviral activity than artemisinin or artanuin-B, two caracteristic molecules for this species 10 . 
Quercetin is also one of the naturally occurring substances found in Artemisia A. annua shown to be effective for a wide range of antiviral use 11 .

In the current context, the genus Artemisia is also one of the candidates for the fight against the global pandemic which has caused a major health crisis. The $A$. annua is considered as a possible treatment for Covid-19, but trials should be performed to assess its effectiveness and determine its adverse effects. Historically, in 2005, a study was carried out by the team of Shi-you Li, confirms that the ethanolic extract of $A$. annua exhibits anti-SARS-CoV activity with EC50 $=34 \pm$ $2.6 \mu \mathrm{g} / \mathrm{ml}^{12}$.

Since new coronavirus appeared, several studies have been carried out to discover natural substances extracted from species of the genus "Artemisia" and examine their potential as inhibitors of the virus.

Recently, in April 2020, the Madagascan president promoted the name of an anti-Covid remedy, called "The CovidOrganics" (CVO): an improved traditional remedy based on Artemisia and medicinal plants from Madagascar. Combined with conventional therapies, herbal teas show an attenuation of respiratory symptoms. It is possible that molecules of $A$. annua play a role in blocking the two main receptors (serum protease, ACE2 receptor) of the cell membrane, i.e. the two main keys that allow the virus to access the cell (Artemisia and Covid-19: the remedy Malagasy boosts Africa, Paris Match, Published on 05/18/2020).

It is known also that the $A$. annua has always been regarded as a reference to clear heat and eliminate dampness. For this reason, $A$ annua acts as a pivotal medicine in the prescription of treatment of SARS 13. Similar, to SARS, Covid-19 is also a coronavirus that causes respiratory syndromes, which start with dampness, with a long latency and courses. The pathogenesis of Covid-19 is mainly characterized by the inward invasion of dampness towards the transformation into heat. Covid-19 treatment should focus on clearing heat, removing dampness and resolving phlegm. Considering the initial clinical manifestations of Covid-19 characterized by pathogen invading Shaoyang gallbladder meridian, $A$ annua is expected to be an essential drug for the treatment of Covid-19 14 .

The natural product tested against this coronavirus reacted largely well against the spike glycoprotein (S) on the surface of SARS-CoV-2 precisely, by binding the domain of SARS$\mathrm{CoV}-2$ spike protein and SARS-CoV-2 main protease 14,15 . In this present study we also targeted furin, a kind of proprotein convertases. Nine compounds from the Artemisia annua are tested by Insilico for their affinity with these three targets. Molecular simulation by density functional theory is carried out on the compounds with the best bond energies.

\section{MATERIALS AND METHODS}

\subsection{Compounds tested}

The genus Artemisia is rich in phytocompounds and the presence of three major families of secondary metabolites has been reported 16 . There are basically nine compounds found in the Artemisia annua. They have been stimulated to determine their anti SARS-Cov-2 potential. These compounds are: Artemisinin, Arteannuin B, Alpha Thujone, Phydroxyacetophenone, Fisetin, Cirsimaritin, Capillin, $\beta$ Sitosterol and Quercetin.

\subsection{Docking targets}

The targets are SARS-CoV-2 main protease (Mp), SARS-CoV-2 receptor binding domain (RBD) and human furin protease
(HF protease). These targets have a crucial role in the virus propagation 14,15 . In addition SARS-CoV-2 Mp is present in most viruses of the coronavirus family and therefore its functioning is widely described in the literature ${ }^{17}$.

\subsection{Docking protocol}

The description of molecular docking, prediction of pharmacokinetic parameters as well as the toxicological property was carried out in our previous article 18 .

\subsection{Density Functional Theory}

Density Functional Theory (DFT) is currently the most successful and promising quantum chemical approach to calculate ground state properties of atoms and molecules. In this paper, all calculations were done by using the B3LYP method and 6-311++G(d,p) basis set 18,19 . The computations for the present work has been performed using the Gaussian 03W 20 and ORCA 4.0.1 21 . All vibrational wavenumbers and geometrical parameters were computed as decrypted in 22 . The topological parameters were determined using Multiwfn software ${ }^{23}$. All the graphs were plotted using Origin 8.0 software ${ }^{24}$ or Multiwfn software.

\section{RESULTS AND DISCUSSIONS}

\subsection{Bioavailability parameters and Toxicity of selected compounds}

When designing a drug, the study of the physico-chemical parameters of the candidate molecule is essential. These parameters predict the behavior of the compound during its oral administration and its bioavailability 25 . Two rules govern the analysis of these parameters: Lipinski and Veber. According to the first rule, the candidate molecules must have a value equal or multiple of 5 . The optimal properties and the corresponding values are: number of active hydrogen atoms (HBD> 5), number of binding sites for hydrogen atoms (HBA> 10), logarithm of the octanol / water partition $(\log \mathrm{P}<5)$, molecular weight $(\mathrm{MW}<500 \mathrm{DA}){ }^{26}$. Beyond two unsatisfied conditions, a candidate molecule is discarded in the drug research process. Our nine compounds from Artemisia annua fulfill these two rules (Table A, Support information).

Also, a predictive evaluation of the possible toxicity of these compounds was made with four different parameters namely Ames toxicity, Carcinogens, Acute oral toxicity and Rat acute toxicity. They have low toxicity whatever the parameters considered (Table B, Support information).

\subsection{Molecular docking}

The search for therapeutic molecules is carried out in different stages. Molecular modelling makes it possible to pre-select the candidate molecules for a given target. The hydrogen bond between the ligand (therapeutic molecule) and the protein/enzyme of the pathogen is studied and a binding energy is measured. A low binding energy corresponds to a good affinity between the ligand and the biological target.

Binding energies range from -2.519 for Artemisinin at the HF protease site to -7.169 for Quercetin at the SARS-CoV-2 Mp site (Table 1). On the SARS-CoV-2 RBD target site, six compounds present in Artesimia sp (66\% of compounds tested) have better binding energies than hydroxychloroquine which is very widely used against Covid-19. And this SARS-CoV-2 RBD target is interesting since this part allows this virus to attach to the host cell. By blocking this receptor with inhibitors like these biomolecules, the virus will not be able to attach itself to 
cells. Recalling, moreover, that the virus is essentially made up of proteins surrounding genetic material and needs the cellular tools to multiply 27 .

Compounds with a better binding energy than one of the reference drugs are shown in 2D to better visualize their interactions with the amino acid residues of the targets (Figure 1). Quercetin, having a better score than the two references, is represented in 3D (Figure 2).

The first two targets (SARS-CoV-2 Mp and SARS-CoV-2 RBD) located on the virus Artemisinin have a better binding energy, twice as small as that of the third human furin protease target, $-4.825,-4.916$ and $-2.519 \mathrm{kcal} / \mathrm{mol}$ respectively. The action of this active compound in $A$ annua would be directed towards the virus rather than host cell protection. This observation is applicable to its derivative Arteannuin B which has binding energies -5.075 and -5.604 and $-3.342 \mathrm{kcal} / \mathrm{mol}$ at the SARS-CoV-2 Mp, SARS-CoV-2 RBD and human furin protease sites respectively. Against SARSCoV-2 RBD these two compounds are better than hydroxychloroquine (Table 1).

However, on the three target sites, Quercetin and Fisetin have the best affinities (Table 1). The antiviral action of Quercetin is already obtained against HIV 28, against influenza virus ${ }^{29}$, herpes virus 30 and against the dengue virus ${ }^{31}$. A recent study has shown that this compound can interfere with $85 \%$ of the functions of the SARS-Cov-2 viral proteins inside human cells. This value rises to $93 \%$ if Quercetin is combined with vitamin D 32 . 
A

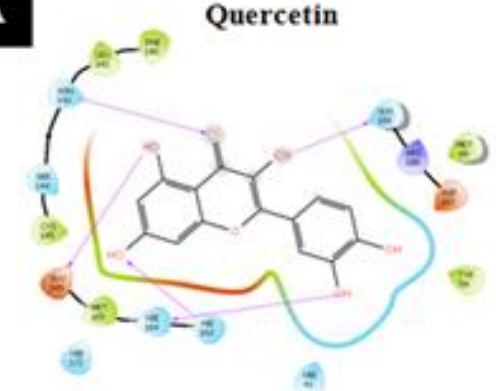

Fisetin

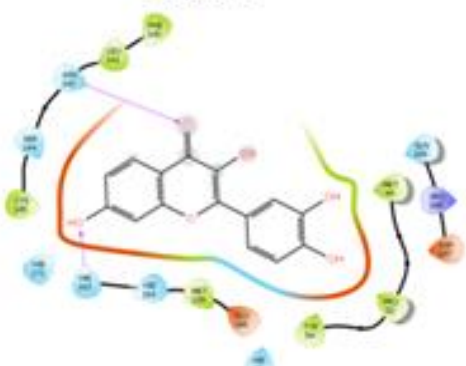

Cirsimaritin

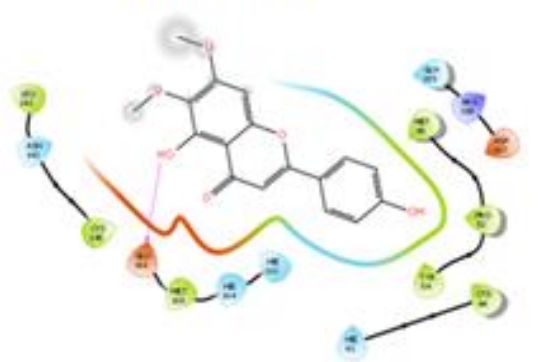

p-Hydroxyacetophenone

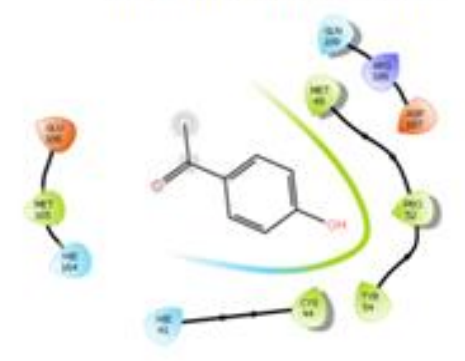

B Quercetin

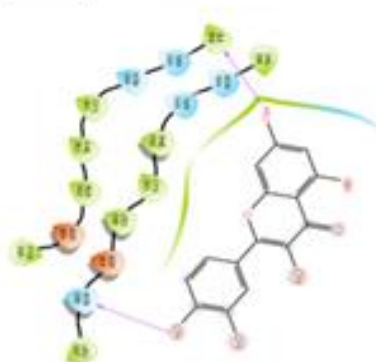

C Quercetin

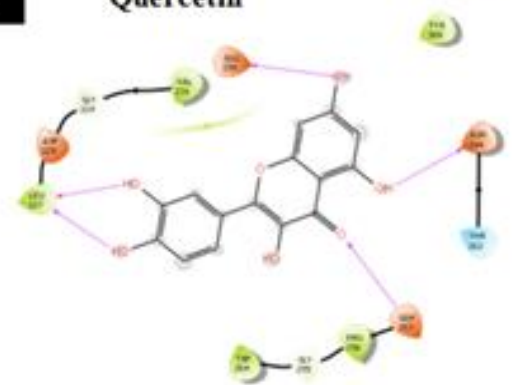

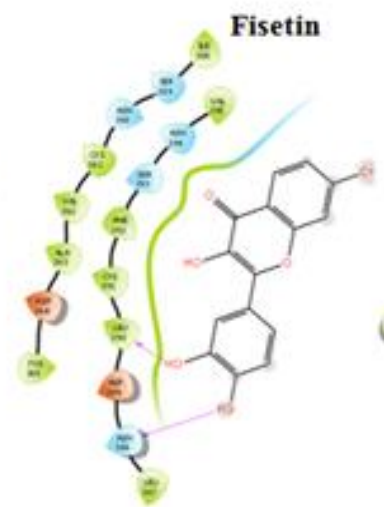

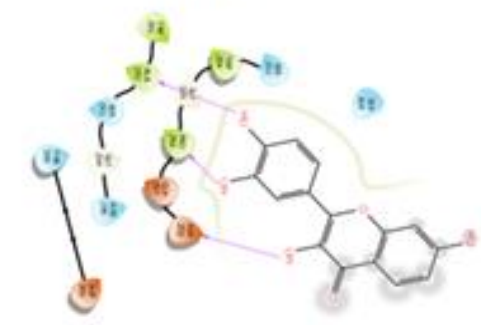

p-Hydroxyacetophenone

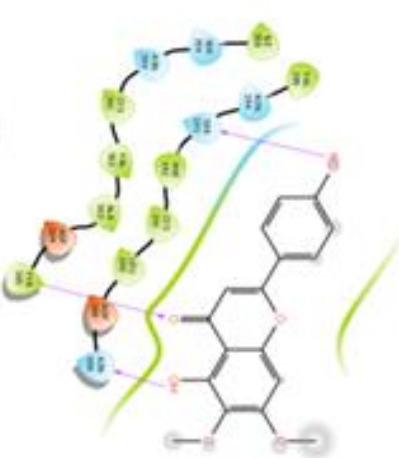

कis

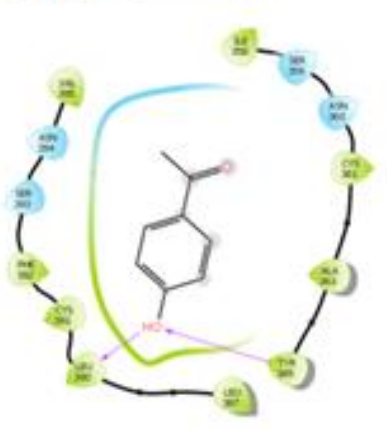

Cirsimaritin

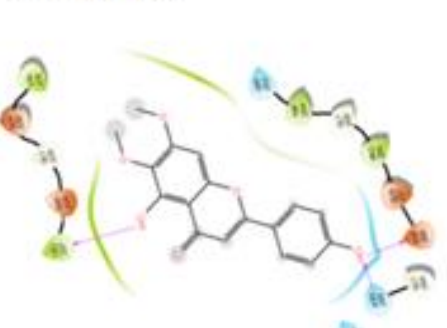

Artemisinin

Arteannuin B
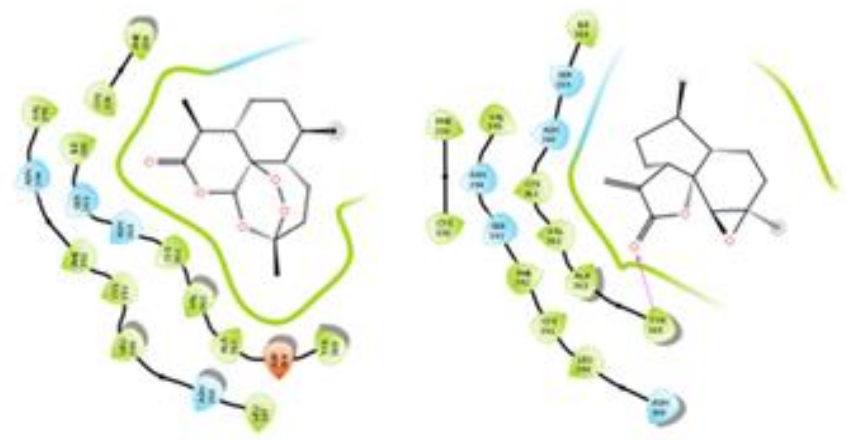

p-Hydroxyacetophenone

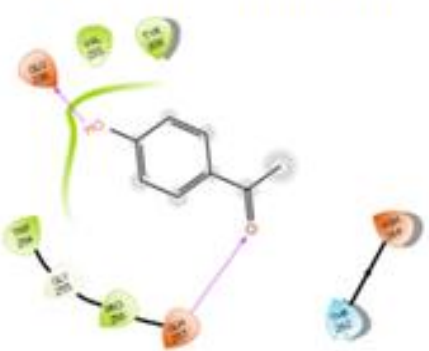

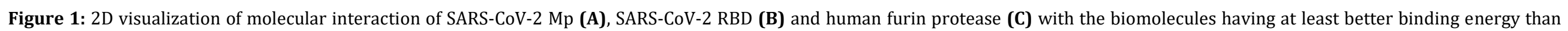
one of standard. 
Journal of Drug Delivery \& Therapeutics. 2021; 11(1-s):71-82

Table 1: Molecular docking of biomolecules with SARS-CoV-2 Mp, SARS-CoV-2 RBD and human furin protease.

\begin{tabular}{|c|c|c|c|c|c|c|}
\hline \multicolumn{3}{|c|}{ SARS-CoV-2 Mp } & \multicolumn{2}{|c|}{ SARS-CoV-2 RBD } & \multicolumn{2}{|c|}{ human furin protease } \\
\hline Compound & BE (kcal/mol) & $\begin{array}{c}\text { Amino acid interaction } \\
\text { (H-bond) }\end{array}$ & $\begin{array}{c}\mathrm{BE} \\
\text { (kcal/mol) }\end{array}$ & $\begin{array}{c}\text { Amino acid } \\
\text { interaction (H-bond) }\end{array}$ & $\begin{array}{c}\mathrm{BE} \\
(\mathrm{kcal} / \mathrm{mol})\end{array}$ & $\begin{array}{c}\text { Amino acid interaction } \\
\text { (H-bond) }\end{array}$ \\
\hline Artemisinin & -4.825 & & -4.916 & - & -2.519 & \\
\hline Arteannuin B & -5.075 & & -5.604 & TYR363 & -3.342 & \\
\hline Alpha Thujone & --- & & --- & & --- & \\
\hline P-Hydroxyacetophenone & -6.182 & & -5.918 & LEU390 ; TYR 365 & -4.875 & GLH257 ; GLU236 \\
\hline Fisetin & -6.907 & ASN142 ; HIE163 & -6.152 & LEU390 ; ASN388 & -5.492 & $\begin{array}{c}\text { ALA292 ; PRO256 ; } \\
\text { ASP258 }\end{array}$ \\
\hline Cirsimaritin & -6.107 & GLU166 & -5.966 & $\begin{array}{c}\text { SER393; TYR365; } \\
\text { ASN388 }\end{array}$ & -5.336 & $\begin{array}{c}\text { LEU227 ; ASN295 ; } \\
\text { ASP258 }\end{array}$ \\
\hline Capillin & -5.489 & & -4.324 & & -3.043 & \\
\hline$\beta$-Sitosterol & -3.646 & & --- & & -3.148 & \\
\hline Quercetin & -7.169 & $\begin{array}{c}\text { ASN142 ; HIE163; } \\
\text { GLU166; } \\
\text { HIE164;GLN189 }\end{array}$ & -6.308 & ILE358; ASN388 & -5.988 & $\begin{array}{c}\text { LEU227 ; GLU236 ; } \\
\text { ASH264 }\end{array}$ \\
\hline Remdesivir * & -7.194 & $\begin{array}{l}\text { GLU:166, GLN:189, } \\
\text { ASN:142 }\end{array}$ & -7.851 & $\begin{array}{c}\text { SER:393, LEU:390, } \\
\text { ILE:332, ALA:363, } \\
\text { ASN:36 }\end{array}$ & -5.544 & $\begin{array}{c}\text { GLY:294, H-bond:- } \\
\text { ASP:306, ASN:295, } \\
\text { SER:253 }\end{array}$ \\
\hline Hydroxychloroquine* & -5.816 & TYR:54, CYS:44 & -4.828 & ASN:360, SER:359 & -4.277 & VAL:231 \\
\hline
\end{tabular}

${ }^{*}$ Remdesivir and Hydroxychloroquine used as references. 
The two flavonols which have the best scores in docking, Quercetin and Fisetin, are classified in category II for Acute oral toxicity with an LD50 between $50 \mathrm{mg} / \mathrm{kg}$ and $500 \mathrm{mg} / \mathrm{kg}$ (Table 1). Although the two compounds have very similar structures, the $\mathrm{OH}$ group at the 5 th position on the A ring and the $\mathrm{B}$ ring as well as the hydroxyl number differ. Quercetin has five hydroxyl groups and 4 for Fisetin. Also, the latter has an $\mathrm{OH}$ at 5 'of the $\mathrm{B}$ ring. The structure-activity study of different flavonoids has shown that the presence of an $\mathrm{OH}$ at the 5'B ring decreases the inhibitory action of polyphenols 33 . $\mathrm{On}$ the other hand, $\mathrm{OH}$ in the A ring, as is the case with Quercetin, is beneficial in the action against rhinovirus 34 .

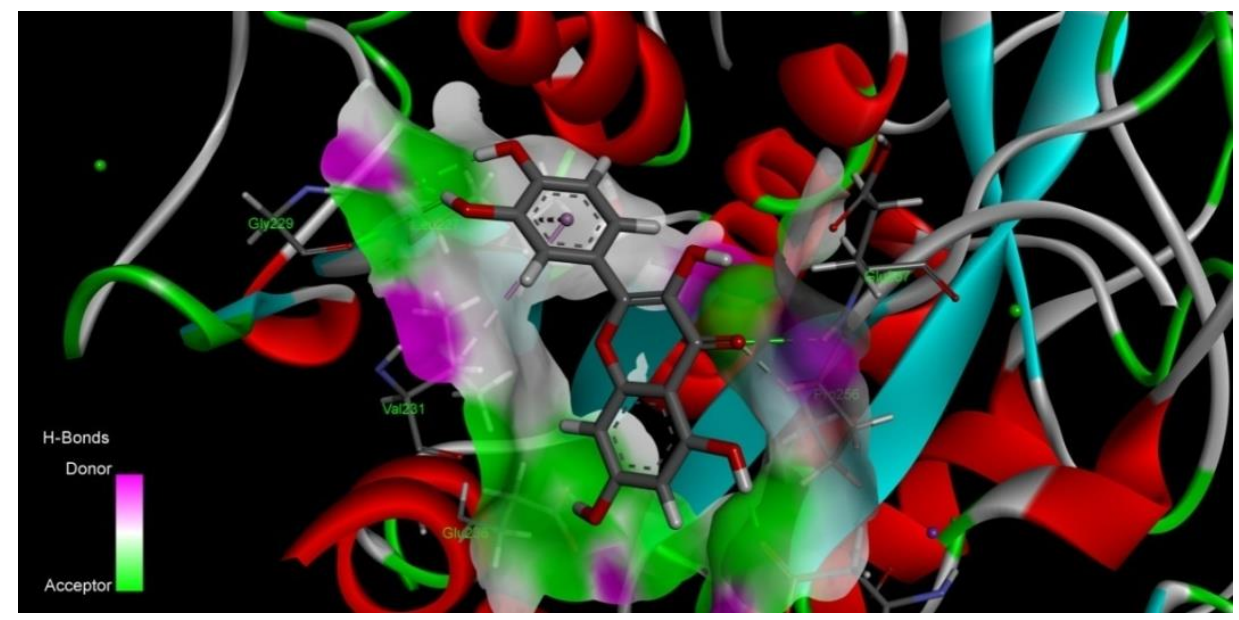

Figure 2: 3D visualization of docking analysis of human furin protease binding with quercetin, better binding energy than the two standards.

On the first two targets, the amino acids that the two flavonols interact with are similar. ASN142; HIE163 bond with Fisetin and for Quercetin ASN142; HIE163; GLU166; HIE164; GLN189 on SARS-CoV-2 Mp (Table 1). Likewise, Fisetin bond with LEU390 and ASN388 on SARS-CoV-2 RBD and Quercetin bond with ILE358 and ASN388. On the other hand, against human furin protease, the binding amino acids are totally different for the two flavonols: ALA292, PR0256, ASP258 for fisetin and LEU227, GLU236, ASH264 for quercetin. In the latter target, the two compounds can be complementary. On this same target, quercetin is better than the reference drugs, remdesivir and hydroxychloroquine (Table 1).

The structural study in particular Density Functional Theory of these two flavonols is crucial to have the possible link of their action with the SARS-CoV-2 virus.

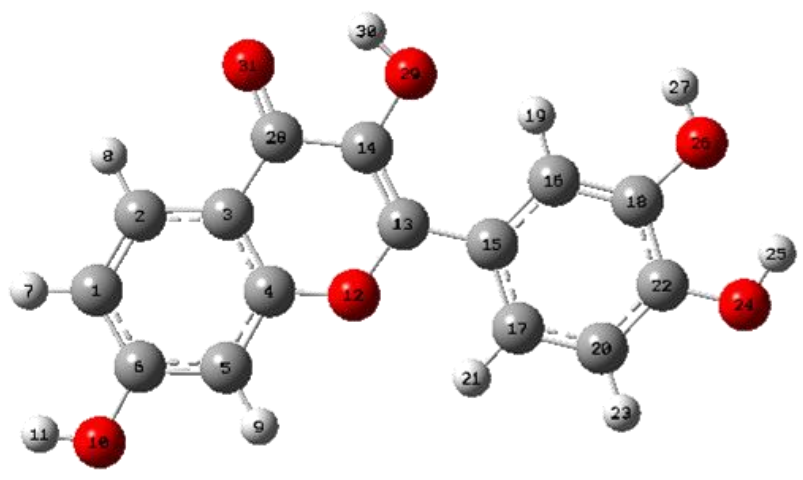

Fisetin

\subsection{Density Functional Theory of Quercetin and Fisetin \\ 3.3.1 Optimized molecular geometry for quercetin and fisetin}

TheB3LYP /6-311++G(d,p) optimized structure of both the molecules Fisetin and Quercetin along with their atom numbering are presented in figure 3. Optimized bond lengths and angles are mentioned in Table C and D (Support Information). The studied compounds retain a C1 point group. The optimized geometry of the studied compounds is in the range of expected bond lengths and bond angles. The $\mathrm{C}-\mathrm{C}, \mathrm{C}-\mathrm{O}, \mathrm{C}-\mathrm{H}$ and $\mathrm{O}-\mathrm{H}$ bond lengths are in the regular order. $\mathrm{C}-\mathrm{C}-\mathrm{C}$ bond angles in the ring and $\mathrm{C}-\mathrm{C}-\mathrm{O}$ along with $\mathrm{C}-\mathrm{O}-\mathrm{H}$ showed well expected bond angles as given in Table C and D (Support Information).

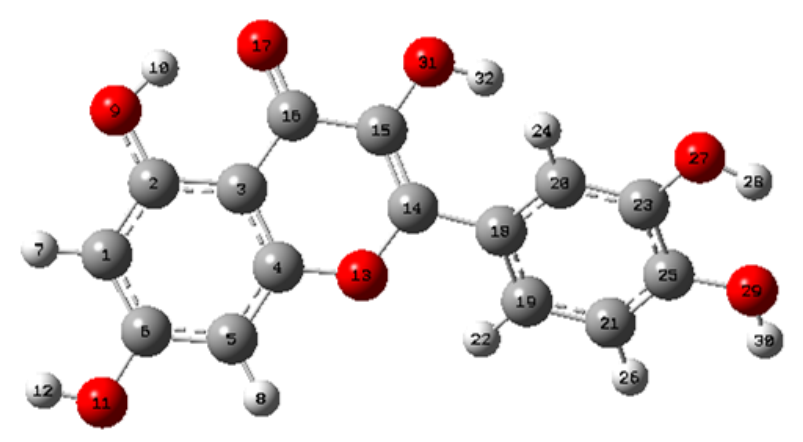

Quercetin

Figure 3: Optimized geometric structure with atom numbering of Fisetin (left) and Quercetin (right), brown-coloured are carbon and red are nitrogen.

Bond lengths of $\mathrm{C}=0$ (R 28-31) in Fisetin is $1.2393 \AA$ while in Quercetin (R 16-17) is $1.2426 \AA$. The 0 - $\mathrm{H}$ bond lengths (R 10$11,29-30,26-27$ and $24-25)$ in Fisetin range from 0.9626 to
0. $9798 \AA$ and the 0 -H bond lengths (R 9-10, 31-32, 27-28 and 29-30) in Quercetin range from 0.9626 to $0.9932 \AA$. 


\subsubsection{Vibrational spectral analysis}

The vibrations frequencies, Raman and IR spectrum analysis of both Fisetin and Quercetin compounds have been obtained by using B3LYP/6-311++G(d,p) basis set along with
Journal of Drug Delivery \& Therapeutics. 2021; 11(1-s):71-82 small scaling factor 0.961 . The fact that no imaginary frequencies were found in prediction implies that the optimized geometry is located at the local lowest point on the potential energy surface.

Table 2: The values of calculated dipole moment $\mu(D)$, polarizability $\left(\alpha_{0}\right)$, first order hyperpolarisability, $\left(\beta_{\text {tot }}\right)$ components of Fisetin and Quercetin.

\begin{tabular}{|c|c|c|c|c|c|}
\hline \multirow{2}{*}{ Parameters } & \multicolumn{2}{|c|}{ B3LYP/6-311++G(d,p) } & \multirow{2}{*}{ Parameters } & \multicolumn{2}{|c|}{ B3LYP/6-311++G(d,p) } \\
\hline & Fisetin & Quercetin & & Fisetin & Quercetin \\
\hline$\mu_{\mathrm{x}}$ & -1.7573 & 4.3252 & $\beta_{\mathrm{xxx}}$ & -156.6432 & 64.2192 \\
\hline$\mu_{\mathrm{y}}$ & -0.5470 & -5.8199 & $\beta_{\mathrm{yxx}}$ & 24.5250 & -130.4996 \\
\hline$\mu_{\mathrm{z}}$ & -0.0008 & -1.1814 & $\beta_{x y y}$ & 46.8354 & 59.0278 \\
\hline$\mu(D)$ & 1.8405 & 7.3467 & $\beta_{\text {yyy }}$ & -4.1032 & -42.9813 \\
\hline$\alpha_{\mathrm{xx}}$ & -92.2677 & -93.7067 & $\beta_{\mathrm{zxx}}$ & -0.0188 & -18.2172 \\
\hline$\alpha_{\mathrm{xy}}$ & 17.4231 & -0.5036 & $\beta_{\mathrm{xyz}}$ & -0.0095 & 13.7173 \\
\hline$\alpha_{\mathrm{yy}}$ & -125.1757 & -136.0758 & $\beta_{\text {zyy }}$ & -0.0039 & -7.8550 \\
\hline$\alpha_{\mathrm{xz}}$ & -0.0075 & -8.3828 & $\beta_{\mathrm{xzz}}$ & 5.7231 & 9.3496 \\
\hline$\alpha_{\mathrm{yz}}$ & -0.0032 & 4.7018 & $\beta_{y z z}$ & 5.2095 & 1.1149 \\
\hline$\alpha_{\mathrm{zz}}$ & -124.6920 & -127.1730 & $\beta_{\mathrm{zzz}}$ & -0.0023 & -0.2199 \\
\hline$\alpha_{0}$ (e.s.u) & $-1.696 \times 10^{-23}$ & $-1.896 \times 10^{-23}$ & $\beta_{\text {tot }}($ e.s.u) & $9.260 \times 10^{-31}$ & $1.892 \times 10^{-30}$ \\
\hline
\end{tabular}

Fisetin has 31 atoms and 87 fundamental vibrations while Quercetin has 32 atoms and 90 fundamental vibrations, both showed $\mathrm{C}_{\mathrm{S}}$ and $\mathrm{C}_{1}$ point group symmetry. The calculated IR and Raman frequencies together with relative intensities are presented in Table $\mathbf{E}$ and $\mathbf{F}$ (Support Information). $\mathrm{C}=\mathrm{O}$ in Fisetin and Quercetin appears at 1612 and $1622 \mathrm{~cm}^{-1}$ respectively. All $\mathrm{C}-\mathrm{H}$ and $\mathrm{C}-\mathrm{C}$ bonds vibrations are in the expected range in both the molecules.

The IR spectrum of quercetin shows an intense and thin band at approximately $3300 \mathrm{~cm}^{-1}$, characteristic of bound $-\mathrm{OH}$ groups. However, the signatures of $-\mathrm{OH}$ bound in Fisetin appear at approximately $3500 \mathrm{~cm}^{-1}$. These differences in intensity and vibration are due to the diversity in the number of $-\mathrm{OH}$ groups and the chemical environment of the two molecules respectively. These bands can be explained by the formation of intramolecular hydrogen bonds, generally of the type $\mathrm{C}=\mathrm{O}---\mathrm{HO}-$ and $-\mathrm{OH}---\mathrm{OH}$. The number of hydroxyl groups as well as their positions can be an influencing factor for the anti-Covid activity against intermolecular interactions (hydrogen-bridge) between Fisetin or Quercetin and virus. Calculated IR and Raman Spectra are displayed in Figure. 4 and 5 for Fisetin and Quercetin. 

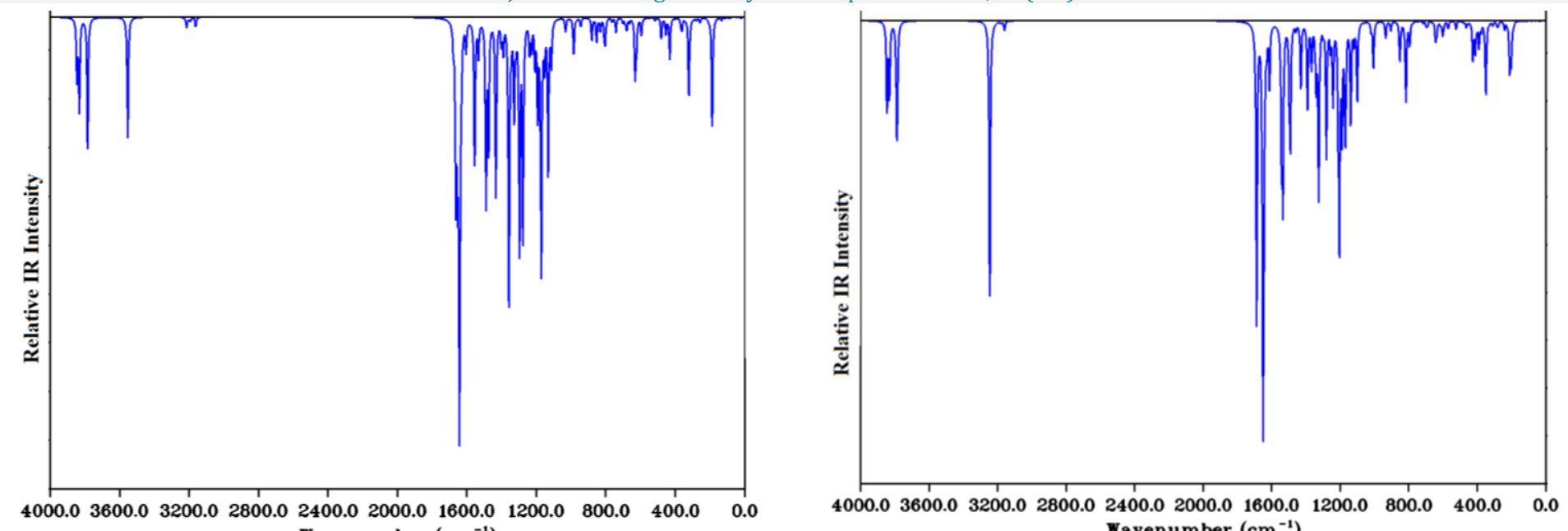
Wavenumber $\left(\mathrm{cm}^{-1}\right.$

Wavenumber $\left(\mathrm{cm}^{-1}\right)$

Figure 4: Infrared spectra of Fisetin(left) and Quercetin (right) using DFT/6-311++G(d,p)
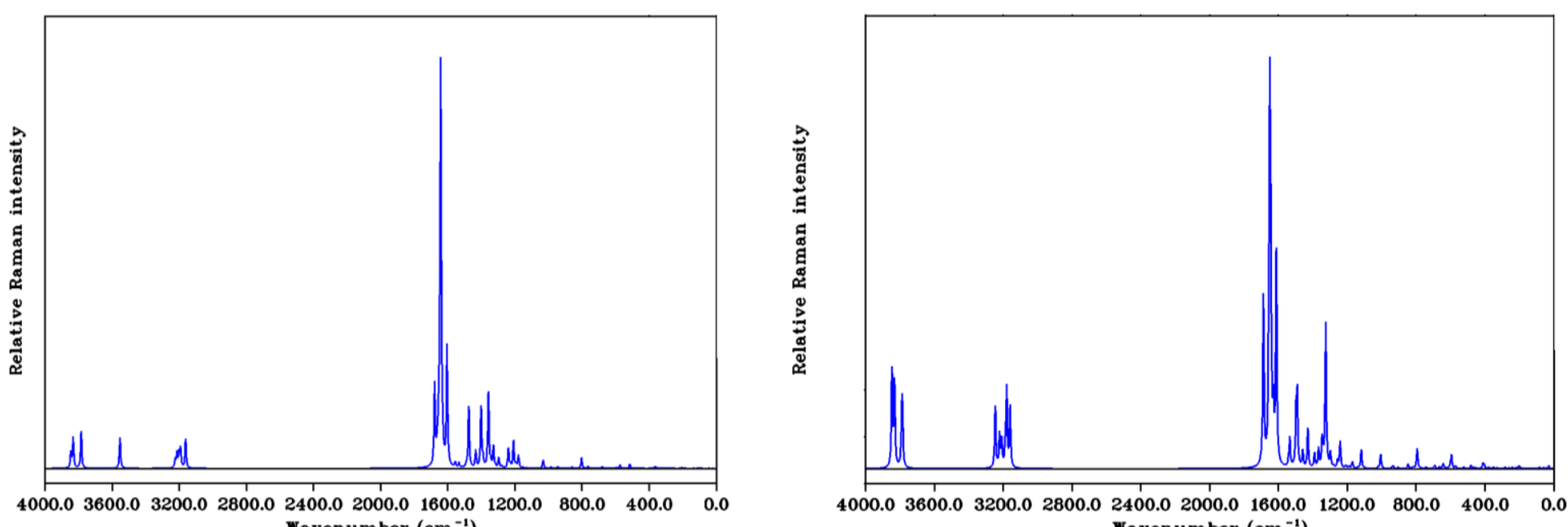

Figure 5: Calculated computational Raman spectra of Fisetin(left) and Quercetin (right) using DFT/6-311++G(d,p) 


\subsubsection{Molecular electrical potential surface}

The contribution of charges may be presented in 3D by utilizing molecular electrical potential (MEP). This prediction facilitates the recognition of interactions of molecule and chemical bond nature. It displays the molecular size, shape, electrostatic potential charge through colour grading. Thus, various physicochemical properties of a molecule can be determined by MEP 35 , like, interaction of nucleic acids with their constituent bases; enzyme-ligand or protein-ligand interactions among others ${ }^{36}$. The different colour in Figure

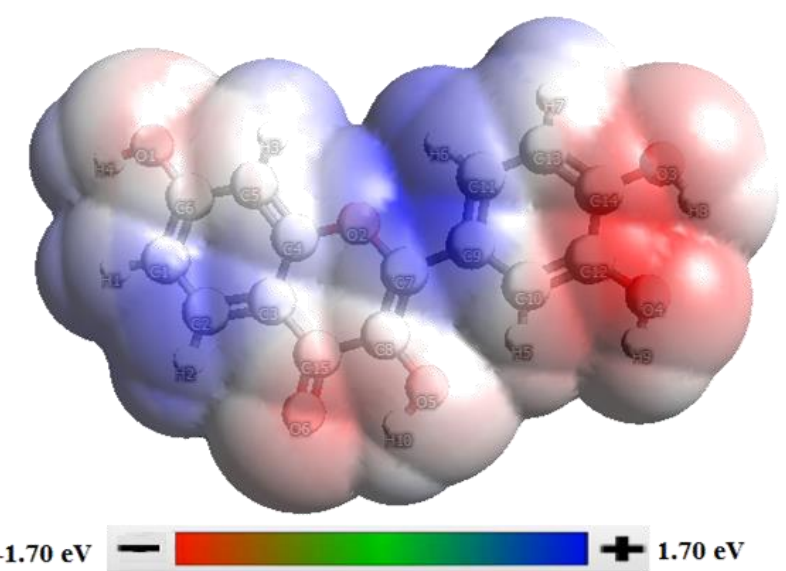

6 shows distinct values of the electrostatic potential at the surface of the compounds.

The electrostatic potential is arranged from smallest (red) to largest (blue). Here, we are showing deepest red for the negative charge and deepest blue for the positive charge. The colour code of the maps is found to be in the range of (deepest red) -1.70 to $+1.70 \mathrm{eV}$ (deepest blue), for the Fisetin and -1.381 (deepest red) to $+1.381 \mathrm{eV}$ (deepest blue) for the Quercetin molecule. The red colour corresponds electrophilic attack and the blue colour shows the nucleophilic attack.

Figure 6: Molecular electrostatic potential (MEP) of Fisetin(left) and Quercetin (right)

\subsubsection{Non-Linear Optical (NLO) property analysis}

The NLO properties of Fisetin and Quercetin were investigated by the DFT/B3LYP technique to establish the NLO character from polarizability, hyperpolarisability and dipole moment calculations. The value of hyperpolarisability have a strong sensitivity to the electron ${ }^{36-38}$

The dipole moment shows highest value at 1.84 and $1.734 \mathrm{D}$ for Fisetin and Quercetin respectively. The values are tabulated in Table 2. The value of the dipole moment increases with the intramolecular interactions.

The hyperpolarisability value for the Fisetin and Quercetin are $9.26 \times 10^{-31}$ and $1.89 \times 10^{-30}$ esu and this large value of

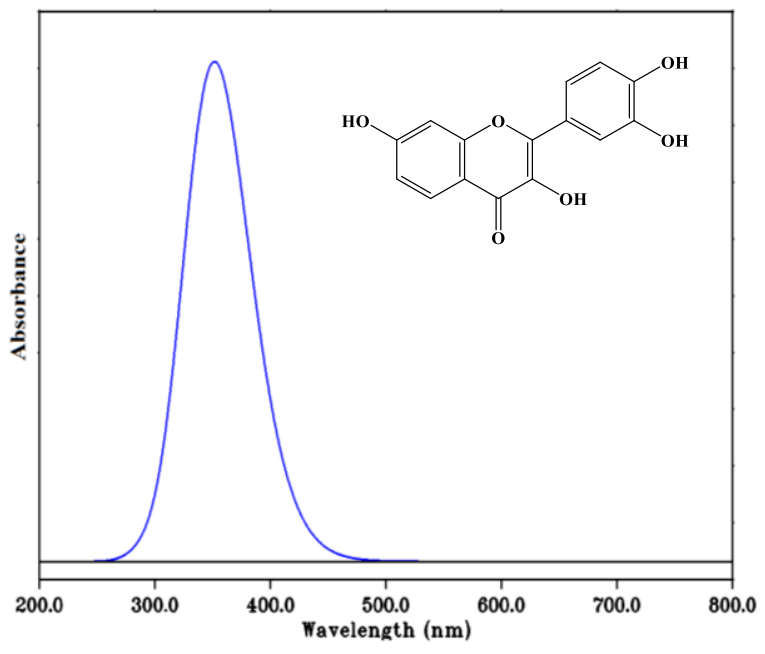

the two molecules implies that they have significant NLO properties.

\subsubsection{UV-Vis spectral analysis and Frontier molecular orbital}

The UV-Vis spectrum of the Fisetin and Quercetin as represented in Figure 7 was computed in gas phase. The electronic transition values for both the molecules are gathered in Table 3. In gas phase, the absorption wavelengths of Fisetin and Quercetin are detected at 352, 303 and 356, $307 \mathrm{~nm}$. These values are similar in gas and solvent phase. Therefore the solvent has no effect on the optical activity of the molecule.

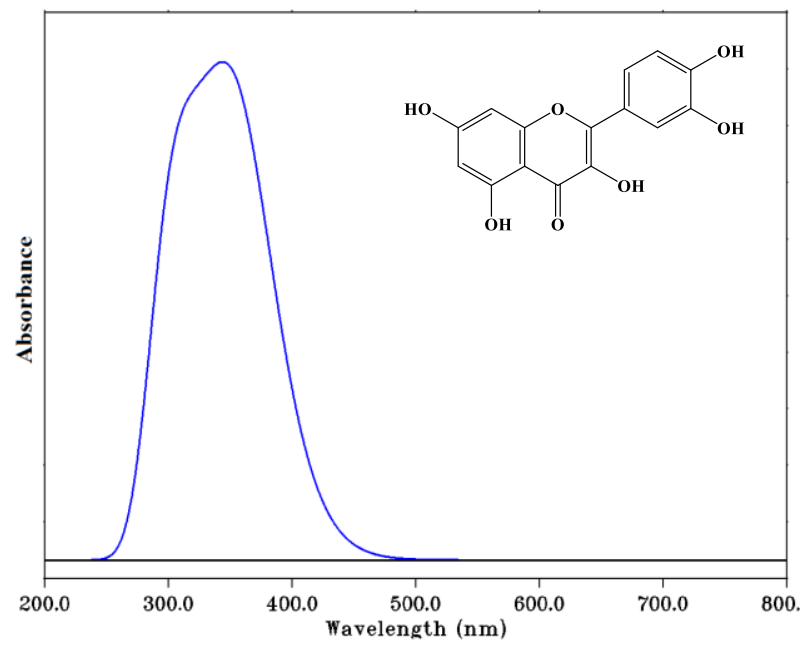

Fig.ure7: UV-Vis spectra of Fisetin (left) and Quercetin (right) (Theoretical-Gas phase) 
The HOMO and LUMO energy diagram is represented in Figure 8. The HOMO and LUMO energy gap informs the molecular chemical stability 39 . The energy difference between the HOMO and the LUMO for Fisetin is $3.835 \mathrm{eV}$ and $4.00 \mathrm{eV}$ for Quercetin as seen in Figure 8. This gap energy is

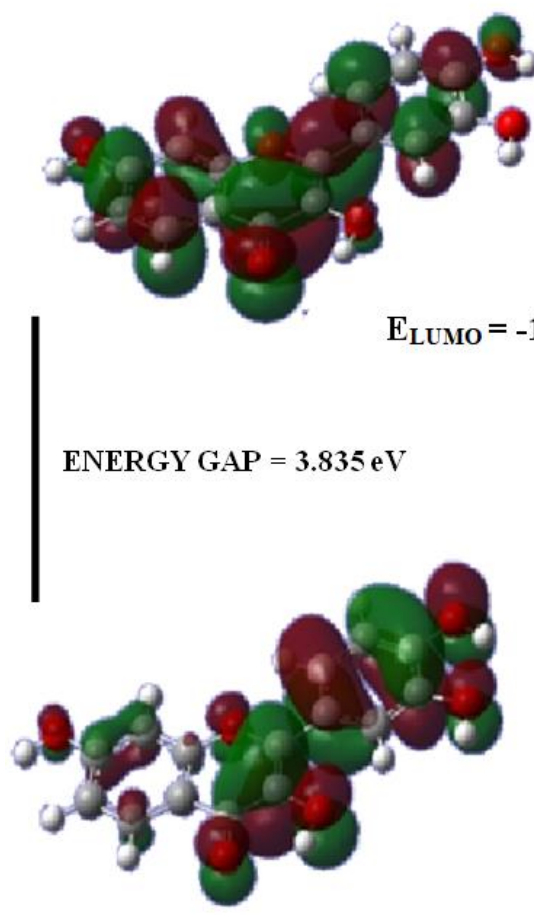

$\mathrm{E}_{\text {Hомо }}=-5.496 \mathrm{eV}$ an essential parameter for electron conductivity characterisation ${ }^{40}$. Parameter like chemical hardness $(\mathrm{CH})$ also contributes to the chemical stability. The $\mathrm{CH}$ of Fisetin is 1.9175 and 2.00 for Quercetin as shown in Table G (Support Information).
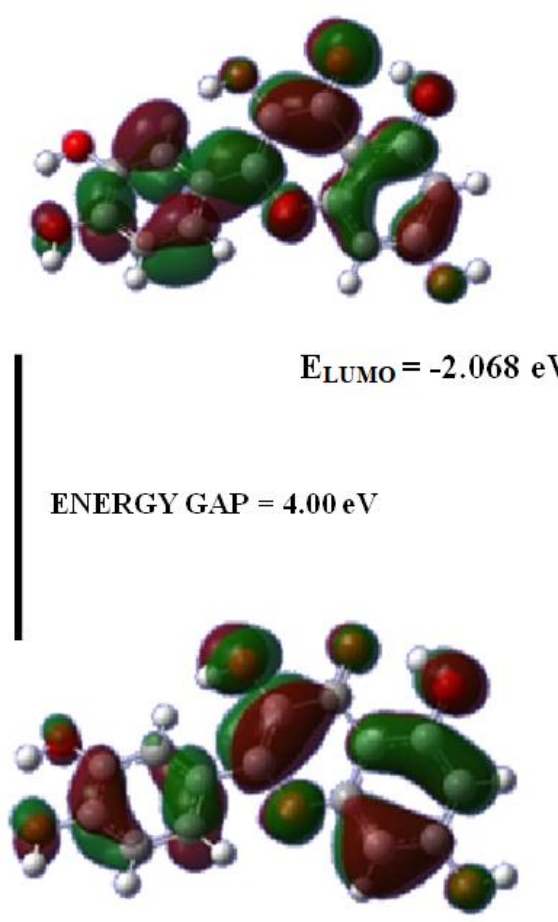

$\mathrm{E}_{\text {номо }}=-6.068 \mathrm{eV}$

Figure 8: Atomic orbital HOMO - LUMO composition of the frontier molecular orbital of Fisetin(Left) and Quercetin (Right).

Similarly, electronegativity corresponding to the attraction of electron towards the atom through the bond was calculated 3.5785 and 4.068 for Fisetin and Quercetin respectively. The electrophilicity index for both molecules with B3LYP method was found 3.3391 and 4.137 for Fisetin and Quercetin respectively. These intermediate values suggested the large energy conversion between the HOMO and LUMO 36-38, 41 .
Both the compounds showed very low chemical softness of 0.5215 and 0.500 for Fisetin and Quercetin respectively, indicating non-toxicity in nature (Table G, Support Information).

Table 3: Comparison of the electronic properties of Fisetin and Quercetin.

\begin{tabular}{|l|l|l|l|l|l|l|l|l|}
\hline \multicolumn{9}{|c|}{ Gas phase Fisetin } \\
\hline
\end{tabular}

In addition, this computer simulation gives leads in the search for inhibitors against this virus. The affinity between the therapeutic molecules and the pathogen is not, however, the only decisive parameter in the choice of candidate drugs, especially in the case of Covid-19. In fact, as described in the literature, the action of the immune system and therefore of its regulation during this condition is crucial ${ }^{42}$.

Finally, the result between a plant extract and its separately tested compounds is different in some cases due to synergistic action (group action). Even if the two 
Elmi et al

characteristic compounds of $A$ annua don't have the best score, however, In vitro tests, the ethanolic extract of this plant has been shown a good activity against the coronavirus 12.

\section{CONCLUSION}

Since the appearance of the new coronavirus at the end of 2019, several types of treatment have been proposed, including herbal medicines. Despite the urgency of the situation, compliance with the protocol for identifying active molecules against this virus remains the only winning way. The flavonoids are the secondary metabolites most exploited for this purpose. In the process of discovering therapeutic molecules, In silico investigations accelerate the search for candidate molecules. In this present study, nine bio compounds detected from the Artemisia annua (Artemisinin, Arteannuin B, Alpha Thujone, P-Hydroxyacetophenone, Fisetin, Cirsimaritin, Capillin, $\beta$-Sitosterol, and Quercetin) are evaluated for their inhibitory effect through molecular docking on three targets essential in the spread of Sars-cov 2. Quercetin and fisetin give promising results. Thereby, a molecular simulation is carried out on these two flavonols (DFT, HOMO, LUMO and gap energies) to evaluate their stability and their activity.

Quercetin is present in many plants and this relatively good availability makes it a serious candidate in the fight against the coronavirus. Invitro tests have shown good anti-SARS-Cov 2 activity but due to its low solubility in water, its administration to living beings remains a challenge.

\section{Declaration of competing interest}

The authors declare that they have no conflict of interest.

\section{Acknowledgements}

We thank Dr Nabil Mohamed, Minister of Higher Education and Research in Djibouti, Dr Jalludin Mohamed, Director of CERD, and Dr Fatouma Mohamed; Director of IRM their constant support.

\section{REFERENCES}

[1] L. E. Watson, P. L. Bates, T. M. Evans, M. M. Unwin, et J. R. Estes, « Molecular phylogeny of Subtribe Artemisiinae (Asteraceae), including Artemisia and its allied and segregate genera », $B M C$ Evolutionary Biology, vol. 2, no 1, p. 17, sept. 2002, doi: 10.1186/1471-2148-2-17.

[2] M. Iranshahi, S. A. Emami, et M. Mahmoud-Soltani, « Detection of Sesquiterpene Lactones in Ten Artemisia Species Population of Khorasan Provinces », Iranian Journal of Basic Medical Sciences, vol. 10, no 3, p. 183-188, juill. 2007, doi: 10.22038/ijbms.2007.5293.

[3] S.-P. He et al., « Development of a sensitive monoclonalantibody-based enzyme-linked immunosorbent assay for the antimalaria active ingredient artemisinin in the Chinese herb Artemisia annua L. », Anal Bioanal Chem, vol. 393 , no 4, p. 1297-1303, févr. 2009, doi: 10.1007/s00216-0082527-5.

[4] D. S. Bhakuni, A. K. Goel, A. K. Goel, S. Jain, B. N. Mehrotra, et R. C. Srimal, « Screening of Indian plants for biological activity: Part XIV », Indian Journal of Experimental Biology, avr. 14, 1990.

https://eurekamag.com/research/007/771/007771446.php (consulté le oct. 18, 2020).

[5] Z. X. Wei, J. P. Pan, et Y. Li, « Artemisinin G: A Sesquiterpene from Artemisia annua », Planta Med, vol. 58, no 3, p. 300, juin 1992, doi: 10.1055/s-2006-961470.

[6] X. Han, X. Ma, T. Zhang, Y. Zhang, Q. Liu, et Y. Ito, « Isolation of high-purity casticin from Artemisia annua L. by high-speed counter-current chromatography », Journal of Chromatography A, vol. 1151, no 1, p. 180-182, juin 2007, doi: 10.1016/j.chroma.2007.02.105.
Journal of Drug Delivery \& Therapeutics. 2021; 11(1-s):71-82

[7] J. Han, M. Ye, X. Qiao, M. Xu, B. Wang, et D.-A. Guo, " Characterization of phenolic compounds in the Chinese herbal drug Artemisia annua by liquid chromatography coupled to electrospray ionization mass spectrometry ", Journal of Pharmaceutical and Biomedical Analysis, vol. 47, $\mathrm{n}^{\circ}$ 3, p. 516-525, juill. 2008, doi: $10.1016 /$ j.jpba.2008.02.013.

[8] N. Q. Liu, F. Van der Kooy, et R. Verpoorte, « Artemisia afra: A potential flagship for African medicinal plants? », South African Journal of Botany, vol. 75, no 2, p. 185-195, avr. 2009, doi: 10.1016/j.sajb.2008.11.001.

[9] M. M. Abid Ali Khan, D. C. Jain, R. S. Bhakuni, Mohd. Zaim, et R. S. Thakur, « Occurrence of some antiviral sterols in Artemisia annua », Plant Science, vol. 75, n 2, p. 161-165, janv. 1991, doi: 10.1016/0168-9452(91)90230-6.

[10] X. Sun et G. R. Whittaker, « Role for influenza virus envelope cholesterol in virus entry and infection », J Virol, vol. 77, n ${ }^{\circ} 23$, p. 12543-12551, déc. 2003, doi: 10.1128/jvi.77.23.1254312551.2003.

[11] J. F. S. Ferreira, D. L. Luthria, T. Sasaki, et A. Heyerick, « Flavonoids from Artemisia annua L. as antioxidants and their potential synergism with artemisinin against malaria and cancer », Molecules, vol. 15, no 5, p. 3135-3170, avr. 2010, doi: $10.3390 /$ molecules 15053135.

[12] S. Li et al., «Identification of natural compounds with antiviral activities against SARS-associated coronavirus », Antiviral Research, vol. 67, no 1, p. 18-23, juill. 2005, doi: 10.1016/j.antiviral.2005.02.007.

[13] S. PENG, «Syndrome Differentiation and Treatment Administration of SARS ». http://caod.oriprobe.com/articles/6268544/Syndrome_Differ entiation_and_Treatment_Administration_of_SARS.htm (consulté le oct. 18, 2020).

[14] R. Dong, X. Xiong, et G. Chen, « Discuss about the application of Artemisia annua prescriptions in the treatment of COVID-19», TMR Modern Herbal Medicine, vol. 3, no 1-7, p. 7, 2020.

[15] A. C. Walls, Y.-J. Park, M. A. Tortorici, A. Wall, A. T. McGuire, et D. Veesler, « Structure, Function, and Antigenicity of the SARSCoV-2 Spike Glycoprotein », Cell, vol. 181, n 2, p. 281-292.e6, avr. 2020, doi: 10.1016/j.cell.2020.02.058.

[16] M. Nigam et al., « Bioactive Compounds and Health Benefits of Artemisia Species », Natural Product Communications, vol. 14, no 7, p. 1934578X1985035, juill. 2019, doi: $10.1177 / 1934578 X 19850354$.

[17] Z. Xu et al., « Nelfinavir was predicted to be a potential inhibitor of 2019-nCov main protease by an integrative approach combining homology modelling, molecular docking and binding free energy calculation », Pharmacology and Toxicology, preprint, janv. 2020. doi: 10.1101/2020.01.27.921627.

[18] A. Elmi, S. A.-J. Sayem, M. Ahmed, et F. Abdoul-Latif, « NATURAL COMPOUNDS FROM DJIBOUTIAN MEDICINAL PLANTS AS INHIBITORS OF COVID-19 BY IN SILICO INVESTIGATIONS », Int J Curr Pharm Sci, p. 52-57, juill. 2020, doi: 10.22159/ijcpr.2020v12i4.39051.

[19] G. A. Petersson, A. Bennett, T. G. Tensfeldt, M. A. Al-Laham, W A. Shirley, et J. Mantzaris, «A complete basis set model chemistry. I. The total energies of closed-shell atoms and hydrides of the first-row elements ", J. Chem. Phys., vol. 89, n ${ }^{\circ}$ 4, p. 2193-2218, août 1988, doi: 10.1063/1.455064.

[20] M.J. Frisch, G.W. Trucks, H.B. Schlegel, G. E. Scuseria, M.A. Robb, R. Cheeseman, J. Montgomer, T. Vreven, K.N. Kudin, J.C. Burant, J.M. Millam, S.S. Iyengar, J. Tomasi, V. Barone, B. Mennucci, M. Cossi, G. Scalmani, N. Rega, G.A. Petersson, H. Nakatsuji, M. Hada, M. Ehara, K. Toyota, R. Fukuda, J. Hasegawa, M. Ishida, T. Nakajima, Y. Honda, O. Kitao, H. Nakai, M. Klene, X. Li, J.E. Knox, H.P. Hratchian, J.B. Cross, V. Bakken, C. Adamo, J. Jaramillo, R. Gomperts, R.E. Stratmann, O. Yazyev, A.J. Austin, R. Cammi, C. Pomelli, J.W. Ochterski, P.Y. Ayala, K. Morokuma, G.A. Voth, P. Salvador, J.J. Dannenberg, V.G. Zakrzewski, S. Dapprich, A.D. Daniels, M.C. Strain, O. Farkas, D.K. Malick, A.D. Rabuck, K. Raghavachari, J.B. Foresman, J.V. Ortiz, Q. Cui, A.G. Baboul, S. Clifford, J. Cioslowski, B.B. Stefanov, G. Liu, A. Liashenko, P. Piskorz, I. Komaromi, R.L. Martin, D.J. Fox, T. Keith, M.A. Al-Laham, C.Y. et A. Nanayakkara, M. Challacombe, P.M.W. Gill, B. Johnson, W. Chen, M.W.Wong, C. Gonzalez, J.A. Pople, « Gaussian 03 », 2004. 
[21] F. Neese, « The ORCA program system », WIREs Computational Molecular Science, vol. 2, no 1 , p. 73-78, 2012, doi: 10.1002/wcms.81.

[22] N. Siddiqui et S. Javed, « Quantum computational, spectroscopic investigations on ampyra (4-aminopyridine) by $\mathrm{dft} / \mathrm{td}$-dft with different solvents and molecular docking studies », Journal of Molecular Structure, vol. 1224, p. 129021, janv. 2021, doi: 10.1016/j.molstruc.2020.129021.

[23] T. Lu et F. Chen, « Multiwfn: A multifunctional wavefunction analyzer », Journal of Computational Chemistry, vol. 33, n 5, p. 580-592, 2012, doi: 10.1002/jcc.22885.

[24] « Origin 8.0, OriginLab Corp., Northampton, MA. »

[25] T. Hou, J. Wang, W. Zhang, et X. Xu, « ADME Evaluation in Drug Discovery. 6. Can Oral Bioavailability in Humans Be Effectively Predicted by Simple Molecular Property-Based Rules? », J. Chem. Inf. Model., vol. 47, n 2, p. 460-463, mars 2007, doi: $10.1021 / \mathrm{ci6003515}$

[26] M. Kowalska, Ł. Fijałkowski, et A. Nowaczyk, « The biological activity assessment of potential drugs acting on cardiovascular system using Lipinski and Veber Rules », déc. 2018, doi: 10.5281/ZENODO.2066519.

[27] Y. Chen, Q. Liu, et D. Guo, « Emerging coronaviruses: Genome structure, replication, and pathogenesis », J Med Virol, vol. 92 , no 4, p. 418-423, avr. 2020, doi: 10.1002/jmv.25681.

[28] C.-Q. Hu, K. Chen, Q. Shi, R. E. Kilkuskie, Y.-C. Cheng, et K.-H. Lee, « Anti-AIDS Agents, 10. Acacetin-7-0- $\beta$-Dgalactopyranoside, an Anti-HIV Principle from Chrysanthemum morifolium and a Structure-Activity Correlation with Some Related Flavonoids », J. Nat. Prod., vol. 57, no 1, p. 42-51, janv. 1994, doi: 10.1021/np50103a006.

[29] W. Wu et al., «Quercetin as an Antiviral Agent Inhibits Influenza A Virus (IAV) Entry », Viruses, vol. 8, nº 1, p. 6, déc. 2015, doi: 10.3390/v8010006.

[30] H. D. Gravina et al., « In vitro assessment of the antiviral potential of trans-cinnamic acid, quercetin and morin against equid herpesvirus $1 »$, Research in Veterinary Science, vol. 91, no 3, p. e158-e162, déc. 2011, doi: 10.1016/j.rvsc.2010.11.010.

[31] K. H. Chiow, M. C. Phoon, T. Putti, B. K. H. Tan, et V. T. Chow, « Evaluation of antiviral activities of Houttuynia cordata Thunb. extract, quercetin, quercetrin and cinanserin on murine coronavirus and dengue virus infection », Asian Pacific Journal of Tropical Medicine, vol. 9, n 1, p. 1-7, janv. 2016, doi: 10.1016/j.apjtm.2015.12.002.

[32] G. V. Glinsky, « Tripartite Combination of Candidate Pandemic Mitigation Agents: Vitamin D, Quercetin, and Estradiol
Manifest Properties of Medicinal Agents for Targeted Mitigation of the COVID-19 Pandemic Defined by GenomicsGuided Tracing of SARS-CoV-2 Targets in Human Cells », Biomedicines, vol. 8, no 5, p. 129, mai 2020, doi: 10.3390/biomedicines8050129.

[33] T. T. H. Nguyen et al., « Flavonoid-mediated inhibition of SARS coronavirus 3C-like protease expressed in Pichia pastoris », Biotechnol Lett, vol. 34, n 5, p. 831-838, mai 2012, doi: 10.1007/s10529-011-0845-8.

[34] T. A. de Toledo et al., « Characterization of flavonoid 3Methoxyquercetin performed by FT-IR and FT-Raman spectroscopies and DFT calculations », Journal of Molecular Structure, vol. 1029, p. 22-27, déc. 2012, doi: 10.1016/j.molstruc.2012.06.058.

[35] J. S. Murry et K. Sen, « Molecular Electrostatic Potential Concepts and Applications », Elsevier, Amesterdam, 1996.

[36] Politzer P, Laurence P R, et Jayasuriya K, « Molecular electrostatic potentials: an effective tool for the elucidation of biochemical phenomena. ", Environmental Health Perspectives, vol. 61, p. 191-202, sept. 1985, doi: 10.1289/ehp.8561191.

[37] H. Sekino et R. J. Bartlett, « Hyperpolarizabilities of the hydrogen fluoride molecule: A discrepancy between theory and experiment? », J. Chem. Phys., vol. 84, n 5, p. 2726-2733, mars 1986, doi: 10.1063/1.450348.

[38] J. Henriksson, T. Saue, et P. Norman, « Quadratic response functions in the relativistic four-component Kohn-Sham approximation ", J. Chem. Phys., vol. 128, n², p. 024105, janv. 2008, doi: 10.1063/1.2816709.

[39] N. M. O’boyle, A. L. Tenderholt, et K. M. Langner, « cclib: A library for package-independent computational chemistry algorithms ", Journal of Computational Chemistry, vol. 29, n 5 , p. 839-845, 2008, doi: 10.1002/jcc.20823.

[40] L. Jn, C. Zr, et Y. Sf, « Study on the prediction of visible absorption maxima of azobenzene compounds. », J Zhejiang Univ Sci B, vol. 6, nº 6, p. 584-589, juin 2005, doi: 10.1631/jzus.2005.b0584.

[41] J. P. Hermann, D. Ricard, et J. Ducuing, « Optical nonlinearities in conjugated systems: $\beta$-carotene », Appl. Phys. Lett., vol. 23, $n^{\circ} 4$, p. 178-180, août 1973, doi: 10.1063/1.1654850.

[42] Y. Jamilloux et al., « Should we stimulate or suppress immune responses in COVID-19? Cytokine and anti-cytokine interventions », Autoimmunity Reviews, vol. 19, n 7, p. 102567, juill. 2020, doi: 10.1016/j.autrev.2020.102567. 